\title{
Determinants of Foreign Exchange Markets
}

\author{
Yasir Yasin Raja, Mr. Naeem-Ullah \\ $M B A$ (executive) \\ (Assistant Professor) \\ Foundation University Islamabad
}

\begin{abstract}
Panel data analysis consisting of four countries was conducted. The study concluded with significant coefficients for relative interest rate, trade balance, terms of trade and net capital inflow. The results indicate that increase in interest rates and adverse trade balance has a negative significant impact on exchange rate while terms of trade and increase in net capital inflow results in favorable exchange rate for the home country. Keywords: Exchange Rate, Relative Interest Rate, Relative Inflation Level, Terms of Trade, Trade Ratio.
\end{abstract}

\section{Introduction}

Foreign exchange marketplace is a market for business of foreign currency. Foreign Exchange takes account of foreign currency outlines, demand for payments, and writings of credit, traveler'scheque with the intention of denominated and allocated in foreign currency. The most important subdivision of foreign currency marketplace is spot market, onward in addition to futures marketplace with currency alternative marketplace. The applicants of foreign exchange marketplace be importers who actually do payment for goods by means of foreign currencies the exporters who take delivery in foreign currencies along with converting it to house currency, collection directors who carry out in foreign legal tender whilst they go away to pay money for or put up for sale the foreign stocks, foreign exchange brokers who actually make a competition of buy or sell instructions, dealers who build marketplace in foreign currencies in addition to the speculators who attempt to revenue from alterations in exchange rates. Exchange rate is reliant on issues for instance Relative Inflation Level, Relative Interest Rate, Trade Ratio, Terms of Trade, Net Inflows and Trade Balance (IMF, 2006).

Foreign exchange marketplace reduces or prevaricate exchange rate jeopardy suitable to unfavorable actions in exchange rates. They supply traders to arbitrage chances and in addition make available venture purpose intended for the traders who are organized to depiction in their organizations to currency danger. This investigation does a thorough examination and learning of macroeconomic determinants which have the same opinion to the contact of genuine exchange rates in Pakistan. To investigate additionally on this effort, a thorough depiction of this is analyzed in this investigation work. If the rate of exchange is appropriately esteemed afterward the consequence of this is not extensive in the macroeconomic presentation of the country. For precedent 35 years in Pakistan, an unchanging rate of exchange has been continued in Pakistan. But in view of the fact that from 2000, the banks in Pakistan have continued the rate to be discrepancy in instrument and this has give the impression to stabilize the currency worth. The decrease of Pakistani currency has stay behind near to $0.6 \%$ for the duration of the preliminary 10 months of financial year 2005-2006. The switch rate distorted from Rs. 59.62 per dollar to Rs. 60.02 per dollar for the duration of this stage (IMF, 2006).

Exchange rate has conventional a great deal of significance in Pakistan owing to acceptance of balanced rate exchange prototype in addition to be acquainted with whether exchange rate consequence variables in macroeconomic variables of the country. In attendance the variables like FDI, GDP, and growth price and trade businesses in Pakistan which are exaggerated by exchange tariffs of the country. This learning will be of assistance us to resolve if in attendance is any undeviating association in exchange rate machinery in the midst of a nation's economic variables. A superior arithmetical relative calculate determination indicate a stronger power of exchange rates on the country's financial system in addition to vice versa. This learning determination as well lend a hand to resolve the familial legal tender risk in addition to exchange value of cash flows denominated in unfamiliar currency may well alter owing to the difference in foreign currency rate (IMF, 2006).

Exchange rates instability assist pressure long period decisions of sponsors by moving quantity of exports against imports. This as well helps in formative the share of administration and confidential savings. This learning determination assist to decide whether switch over rates are prejudiced by authority trade and financial system of country, as well as reason for example Relative Inflation Level, Relative Interest, Rate Terms of Trade, Trade Ratio, Net Inflows and Trade Balance and if they have a consequence on, the degree to which they power the exchange speed of Pakistan (IMF, 2006).

Advanced rate of interest rate for an asset in a particular currency be able to shove up the command for Pakistani rupee which determination add to the exchange rate in errand of Pakistani Rupee. Dissimilar inflation charge as a consequence of buy authority of Pakistani Currency strength depreciates more rapidly than currency 
of some additional country, which determination put in to engagements of exchange rate. Government might in addition to inflict constraint on currency business; Pakistani Government possibly will in addition pay money for or put up for sale the currencies in enormous currencies to regulate the current exchange rate. Rise in investment chances in Pakistan show the way to incursion of foreign currency money to Pakistani Rupee in that way transport downward the exchange rate. Speculators as well as treasury directors' pressure exchange tempos pressure group in exchange rates by buying and selling foreign currencies with prospect of superior proceeds by taking advantage of market inefficiencies. The quanta of their process have an effect on the exchange rates (IMF, 2006).

\section{Literature Review}

Hong and Lee (2003) and Meese and Rogoff (1990) made use of non parametric method to document with the intention of still non parametric models were not clever enough to do better than random walk model in the meadow of exchange rate forecast. Meese and Rogoff (1991), as well included non-linearity keen on their econometric modeling of exchange rate performance other than completed so as to such addition did not look up the forecasting competence of economic models. Rossi (2006) disputed that segment of exchange rate variations gave details by economic models were approximately zero. In experiential study of nominal exchange speed travels, she recognized with the intention of some countries accidental walk models that were unsuccessful to give details exchange rate pressure group. This judgment discarded the conversation that macroeconomic variables have no connection with exchange rate pressure group. As a consequence, the negative response of macroeconomic models capacity not is outstanding to their insignificance by means of exchange rate to a certain extent outstanding to their wobbly relationship above time. The query, whether obtainable economic models of exchange rate hit accidental walk model or not, is anxious but current respond to this query is that the Random walk models better clarify the activities in exchange rate excluding they pay no attention to economic assumptions (Meese and Rogoff, 1983; and Rivard \& Thomas, 2007). Researchers have contrasted economic representations with random walk and additional autoregressive methods but no employment has been accomplished on what the widespread reasons are that cause variations in emerging Asian economies. On the other hand, many researchers encompass renowned that neural system replica of exchange rate forecasting contain the authority to beat the random walk model. But answers of preponderance of these representations are pedestal on out of example forecasting aptitude not on in the example forecasting. for instance, Kuan and Liu (1995) practical Neural Networks systems on daily money prices and account subordinate absent of sample forecasting mistakes when contrasted to individuals of random walk models. Their answers were sustained by Brooks (1997). In addition, important investigations have been carrying out on belongings of outliers in the sequence. Nearly everyone usually account belongings are prejudiced parameter, which damage the forecasting presentation of exchange rate models (Ledolter, 1989; Hotta, 1993; Gao, 2000; and Ghirmai, 2011).

Currencies trade inside foreign exchange markets pedestal on supposed exchange rates (Dada, 2004). An augment (reduced) in the swap rate, extracted in indirect terms, earnings that the familial currency is appreciating (depreciating) against the foreign currency. The genuine exchange rate that is described as the supposed exchange rate increased by the ratio of cost levels, events the comparative acquiring power of the currencies. An augment in the real exchange velocity $(\mathrm{Rd} / \mathrm{f})$ entails a decrease in the relative acquiring power of the domestic currency. an assortment of studies have been approved out to approximate relationship involving Relative Interest Rate, Trade Balance, Relative Inflation Level, Terms of Trade, Trade Ratio and Net Inflows and Exchange rates, which have stated mixed consequences. These studies were by Akhtar and Hilton (1984), Cushman (1983), Steinherr and Peree (1989), Svensson and Persson (1989), Pozo (1992), Kumar and Dhawan (1991) and Kenen and Rodrik (1986).

Lanyi and Suss (1986) have exposed from side to side their investigate paper that exchange rate unpredictability have an effect on the domestic currency in addition to prices of exports and imports and basket the international trade. It is unspecified with the intention of an augment in risk determination guide the risk averter to fewer risky businesses. This is established by De Grauwe (1988) from side to side his investigate paper. The risk averter takes keen on reflection the most awful probable situation and for this reason these radically turn down the option of revenues. An extreme real rate of exchange has unenthusiastic wellbeing consequence i.e. it decrease the stage of trade completed worldwide and have an effect on investment conclusions thus hindering economic expansion. An exchange rate is the cost of solitary currency comparative to a further one. Alteration in the exchange rate has an effect on the cost of exports and imports in addition to therefore collective demand. for instance, a subordinate euro comparative to supplementary currencies construct European exports cheaper in world's marketplace along with foreign harvest sold in Europe that are the European imports which are additionally expensive. Consequently, an inferior euro is supposed to reason European exports to augment and imports to turn down which will source the AD, the aggregate demand curve to move to the right. On the other hand, a stronger euro decreases exports and lifts up the imports, and the AD curve moves to the left."It is significant to appreciate that in attendance there is dissimilarity among referring to 
an individual currency as well as an exchange rate. An individual can grasp an entity currency (for instance, in a EUR 100 million set down), other than an exchange rate refers to the cost of single currency in conditions of one more (for instance, the exchange rate among the EUR and USD). An entity currency knows how to be remarkable, but present are forever two currencies concerned in an exchange rate: the price of one currency comparative to an additional. The exchange rate is the numeral of units of single currency (described the price currency) that one component of one more currency which is also described as the base currency will buy. A corresponding way of recitation the exchange rate is as the price of one component of the Base Exchange in conditions of the price currency. A reduce in the exchange rate would signify that the euro expenses a smaller amount or so as to fewer U.S. dollars are desired to buy one euro. In supplementary language, a refuse in this exchange rate specify that the USD is realizing next to the EUR or, consistently, the EUR is devaluing next to the USD. The exchanges rates explained on top of are referred to as ostensible exchange rates. This is to differentiate them on or after real exchange rates, which indices over and over again build by economists as well as other marketplaces forecasters to review alterations in the relative purchasing authority of one currency as contrasted with a different one. Creating these index necessitate regulate the nominal exchange rate by means of the price stages in every country of the currency couple therefore the name is real exchange rates, in arrangement to contrast the comparative purchasing power among countries (Milton, 1953; and Kashyap\& Jeremy, 2007; and Dreher et al, 2008)

Even though genuine exchange rates are able to exert a number of powers on nominal exchange rate movements, they are merely single of a lot of issues; it is able to be very difficult to unscramble each and every one of these inter-relationships in a very multifaceted and vibrant Foreign exchange marketplace. For this reason, it is supposed to not be astonishing with the intention of real exchange rates, which reflect changes in comparative purchasing influence which encompass poor pathway documentation as a forecaster of expectations nominal exchange rate arrangements (Milton, 1953; Rao, 1989; and Horne \&Wachowicz, 2000).

\section{Sample:}

\section{Methodology}

Our sample includes four countries because these countries have developing economies and the data for different variables used in the study is available throughout the sample period.

Data:

Data for different variables was obtained from IMF CD-ROM, World Bank, Government of Pakistan Statistics. The primary reason for using these sources was the authenticity of these figures. The data consisted of 43 countries years' observation. The observations of each variable were obtained from the years 1970-2012 for every country that is included in this sample.

\section{Regression Model:}

The panel regression model is as follows

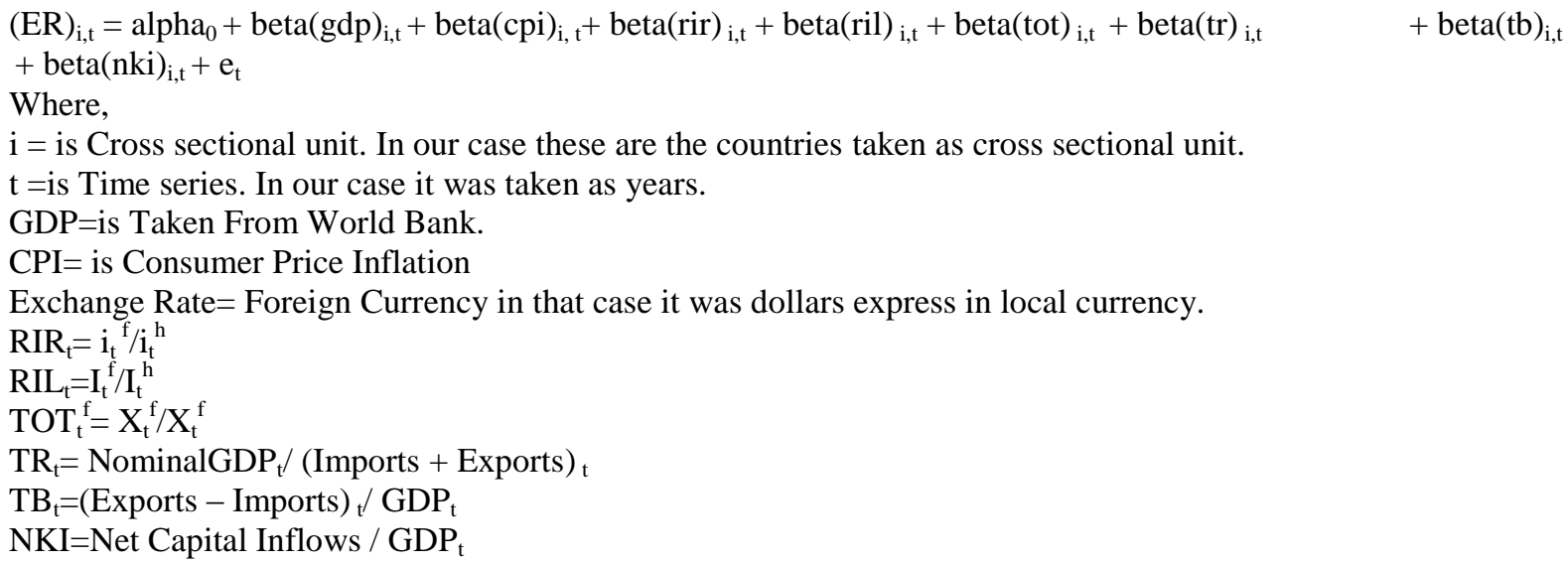

Panel Data Regression Model:

We used three panel data regression models which are

1.) Common Effect model

2.) Fixed effect model

3.) Random effect model 


\section{1.) Common Effect Model:}

The underline assumption of common effect model is homogeneity of Cross-sectional units. The common effect model is as under.

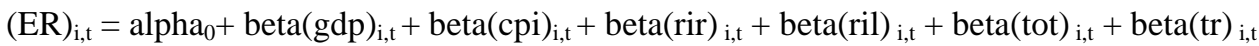
$+\operatorname{beta}(\mathrm{tb})_{\mathrm{i}, \mathrm{t}}+\operatorname{beta}(\mathrm{nki})_{\mathrm{i}, \mathrm{t}}+\mathrm{e}_{\mathrm{t}}$

Here it assumes that intercept will be save for all cross-sectional unit, however there is a serious disadvantage to this simplicity. Our sample consists of countries which although are developing economies but are different in the context of culture, economic control etc. thus we may not obtain the robust and generalize able results using common effect model.

\section{Heteroskadascity Test:}

Most of the panel data variables are prone to heteroskadascity bias. That is the presence of outlier's data. In order to detect heteroskadascity

We will use Breusch-Pagan/Cook-Weisberg test for heteroskadascity under the following hypothesis

H0: There is no heteroskadascity in the data.

H1: There is heteroskadascity in the data.

The p-value of 0.05 or less will indicate that our data is having the problem of heteroskadascity. Once the heteroskadascity is detected we will conduct all tests using the robust standard errors.

\section{2.) Fixed Effect Model:}

The assumptions of fixed effect model show that all the cross-sectional have unique intercept. Thus it recognizes the heterogeneity of the cross-sectional units However; it assumes that other characteristics are homogenous. The fixed effect model in our case is as follows.

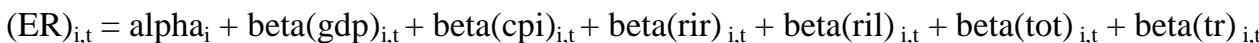
+ beta(tb) $)_{i, t}+$ beta$\left._{(n k i)}\right)_{i, t}+e_{t}$

However, it does not control the biasness that may originate from error terms. Further in the cases where we have fewer firm year observation, then fixed effect model will have less Robust results than random effect model.

\section{3.) Random Effect Model:}

This model controls for the biasness caused by the error term. It is ideal,when firmyear observations are low. Random effect model used in our study is elaborated as follows

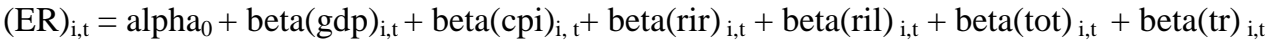
$+\operatorname{beta}(t b)_{i, t}+\operatorname{beta}(n k i)_{i, t}+e_{t}$

\section{Housman Tests:}

Mostly fixed effect model and random effect model provides same results but occasionally that may differ. In this case in order to identify which model is providing more Robust and generalize able results, we would conduct Housman test following hypothesis using stata 10.

H0: Fixed effect results are accepted.

H1: Random effect results are accepted.

A p=value of 0.05 or less will enable us to reject Null hypothesis (H0) and accept alternative hypothesis (H1). 


\section{Results andDiscussions}

\section{Table 1 Correlation Test Result}

\begin{tabular}{r|rrrrrrr} 
& Iner & rir & ril & tot & tr & tb & nki \\
\hline Iner & 1.0000 & & & & & & \\
rir & -0.2033 & 1.0000 & & & & & \\
ril & -0.2314 & 0.3900 & 1.0000 & & & & \\
tot & 0.3432 & -0.0116 & 0.0023 & 1.0000 & & & \\
tr & -0.3079 & -0.1972 & -0.0741 & -0.0036 & 1.0000 & & \\
tb & 0.1637 & -0.1698 & -0.1233 & 0.7834 & 0.3919 & 1.0000 & \\
nki & 0.3320 & 0.0960 & 0.0408 & 0.1110 & -0.4152 & -0.1469 & 1.0000
\end{tabular}

It represents the correlation matrix of our variables of study. It can be clearly seen that there are no independent variables that are significantly correlated with one another. This indicates the fact that our data is free from the problems caused by multi-correlation.

Appendix1

\begin{tabular}{r|rrrrrr}
\hline lner & Coef. & Std. Err. & $t$ & P $>|t|$ & [95\% Conf. Interval] \\
\hline rir & -1.247312 & .4285893 & -2.91 & 0.004 & -2.093538 & -.4010856 \\
ril & -.503202 & .1899146 & -2.65 & 0.009 & -.878178 & -.1282259 \\
tot & $\mathbf{4 . 2 4 9 9 7 2}$ & 1.614859 & 2.63 & 0.009 & 1.061521 & $\mathbf{7 . 4 3 8 4 2 3}$ \\
tr & -.2251597 & .0712568 & -3.16 & 0.002 & -.3658523 & -.084467 \\
tb & -.8521094 & 6.884977 & -0.12 & 0.902 & -14.44612 & 12.7419 \\
nki & $\mathbf{4 3 . 8 7 1 3 6}$ & 14.83161 & 2.96 & 0.004 & 14.58715 & $\mathbf{7 3 . 1 5 5 5 6}$ \\
- cons & .9602573 & 1.666435 & 0.58 & 0.565 & $-\mathbf{2 . 3 3 0 0 2 8}$ & $\mathbf{4 . 2 5 0 5 4 2}$ \\
\hline
\end{tabular}

We started our analysis by estimating the common effect model whose results are reported in Appendix 1. The result indicates that RIR, RIL and TR have negative significant coefficients while TOT and NKI have positive significant coefficients. However we cannot rely on these results because we have not tested our data for heteroskadascity.

\section{Hettest Result}

\section{Breusch-Pagan / Cook-Weisberg test for heteroskedasticity Ho: Constant variance Variables: fitted values of lner}

$\begin{array}{ll}\operatorname{chi}(1) & 34.40 \\ \text { Prob }>\text { chi2 } & 0.0000\end{array}$

The heteroskadascity test results reported above has that a p-value of 0.00 that indicates that we accept the alternative hypothesis where we accept the presence of heteroskadascity data. After detecting heteroskadascity we winsorize data for outliers and will conduct all panel data estimation techniques with robust standard errors.

Table 2.1

\begin{tabular}{r|rrrrrr}
\hline \multirow{2}{*}{ Iner } & Coef. & Robust \\
& Std. Err. & $t$ & P $>|t|$ & [95\% Conf. Interval] \\
\hline rir & -1.247312 & .3760583 & -3.32 & 0.001 & -1.989819 & -.5048052 \\
ril & -.503202 & .1312097 & -3.84 & 0.000 & -.7622685 & -.2441355 \\
tot & $\mathbf{4 . 2 4 9 9 7 2}$ & 1.190936 & 3.57 & 0.000 & 1.898534 & 6.60141 \\
tr & -.2251597 & .0561604 & -4.01 & 0.000 & -.3360453 & -.1142741 \\
tb & -.8521094 & 4.964298 & -0.17 & 0.864 & -10.65385 & 8.949628 \\
nki & $\mathbf{4 3 . 8 7 1 3 6}$ & 14.7496 & 2.97 & 0.003 & 14.74908 & $\mathbf{7 2 . 9 9 3 6 4}$ \\
cons & .9602573 & 1.17707 & 0.82 & 0.416 & -1.363803 & 3.284318 \\
\hline
\end{tabular}

Table2.2 Fixed Effect Model

\begin{tabular}{|c|c|c|c|c|c|c|}
\hline \multicolumn{7}{|c|}{$\begin{array}{l}\text { Robust } \\
\text { Robiez. }\end{array}$} \\
\hline lner & Coef. & std. Err. & t & $P>|t|$ & [95\% Conf. & Interval] \\
\hline rir & -.2864538 & .9334114 & -0.31 & 0.759 & -2.134543 & 1.561636 \\
\hline ril & -.0629658 & .1820026 & -0.35 & 0.730 & -.4233183 & .2973867 \\
\hline tot & 6.698476 & 1. 69199 & 3.96 & 0.000 & 3. 348454 & 10.0485 \\
\hline $\operatorname{tr}$ & -.106281 & .0655308 & -1.62 & 0.107 & -.2360274 & .0234653 \\
\hline$t b$ & -24.03272 & 6.132673 & -3.92 & 0.000 & -36.17499 & -11.89045 \\
\hline _ nki & -39.48752 & 18.18159 & -2.17 & 0.032 & -75.48581 & -3.489237 \\
\hline _cons & -1.513921 & 1.754037 & -0.86 & 0.390 & -4.986793 & 1. 958951 \\
\hline
\end{tabular}


2.3Random Effect model

\begin{tabular}{|c|c|c|c|c|c|c|}
\hline lner & Coef. & $\begin{array}{l}\text { Robust } \\
\text { std. Err. }\end{array}$ & $\mathrm{z}$ & $P>|z|$ & [95\% Conf. & Interval] \\
\hline rir & -2.405429 & .7112342 & -3.38 & 0.001 & -3.799422 & -1.011435 \\
\hline ril & -.2555702 & .1983883 & -1.29 & 0.198 & -.6444041 & .1332636 \\
\hline tot & 3.323701 & 1.239853 & 2.68 & 0.007 & .8936341 & 5.753768 \\
\hline $\operatorname{tr}$ & -.0067045 & .0592566 & -0.11 & 0.910 & -.1228454 & .1094364 \\
\hline$t b$ & -12.84275 & 5.685978 & -2.26 & 0.024 & -23.98706 & -1.698434 \\
\hline $\begin{array}{r}\text { nki } \\
\text { cons }\end{array}$ & $\begin{array}{r}-48.886 \\
2.392649\end{array}$ & $\begin{array}{l}19.06606 \\
1.532619\end{array}$ & $\begin{array}{r}-2.56 \\
1.56\end{array}$ & $\begin{array}{l}0.010 \\
0.118\end{array}$ & $\begin{array}{r}-86.2548 \\
-.6112292\end{array}$ & $\begin{array}{l}-11.5172 \\
5.396528\end{array}$ \\
\hline
\end{tabular}

Table 2.1, Table 2.2, Table2.3 outlines the results obtain by estimating Common effect model, Random effect model and fixed effect model with robust standard errors.

The common effect model indicates that RIR, RIL, TR have negative significant coefficients while TOT and NKI have positive significant coefficients. However we are not in the position yet to finalize our results as common effect model has a serious disadvantage of assuming cross sectional homogeneity.

In order for more Robust result we conducted fixed effect model and random effect models with robust standard error. The fixed effect model indicates positive significant coefficients for TOT and negative significant of TB and NKI. Whereasresults of random effect model indicate RIR, RIL, TB and NKI have negative significant coefficients while TOT haspositive significant coefficients.

The results random effect model and common effect model are in serious disagreement with each other. This in order to select best model that gives most generalize able androbust result we will run Housman Test.

\section{Housman Test Result}

Test: Ho: difference in coefficients not systematic

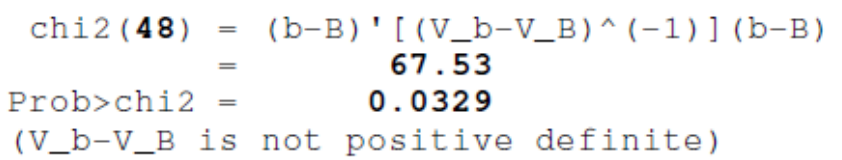

The Housman test was carried under the alternative hypothesis that indicated to accept the results of random effect model. The result clearly indicates p-value of 0.03 by virtue of which you will accept result of random effect model.

RIR:

The Relative interest rate has negative significant coefficients that indicate if interest rate in home country increases with respect to foreign country then exchange rate will favor more in foreign country. Our sample consists of developing countries where general interest rate is higher and thus exchange rate suffers adversely. Our results are in conformity with Interest Rate Parity Theory and previous researches like ZakariaM, Ahmed andIqbal M, 2007.

TOT:

Terms of Trade indicates whether home country is offering favorable terms and conditions to facilitate to foreign trade have a positive significant coefficient. This clearly indicates that a more open policy towards trade have positive significant impact exchange rate of home country results are conformity to previous researches like BailleR.T \& McMahon P.C 1989.

TB:

Trade Balance indicates the difference between exports and imports of host and foreign country. The negative significant coefficients of this variable indicate that when host country is importing more its exchange rate will suffer a loss. Our results are conformity with theory and past researchlike Wright J.H, 2003.

NKI:

Net capital Inflow has negative significant coefficients indicates that more and more investments are made in the home country, the exchange rate of home country will improve with respect to foreign country. As our exchange rate is express in terms of home country one unit of foreign currency and increase in foreign currency will improve position of local currency. Then we will be paying less units of local currency to buy one unit of foreign currency.

\section{Conclusion}

The study aim was conducted to see the determinants of exchange rate in developing countries. We constructed panel data of four developing countries with 172 firm years' observations of every variable. Our results concluded with a positive significant coefficient for RIR, RIL and NKI. Our results suggest that interest 
rate should be kept at acceptable levels as it adversely affects the home countries exchange rate. Whereas an adverse Trade Balance (TB) has a negative significant impact on exchange rate. The government should try its level best to increase capital inflows of its country by offering incentives to the foreign investors that will have a positive significant impact on the exchange rate.

\section{References}

[1]. Hota.L.K, (1993). "The Effect of Additive Outliers on The Estimates from Aggregated and Disaggregated ARIMA Models", International Journal of Forecasting Vol 9, pp. 85-93

[2]. Ledolter.J, (1989). "The Effect of Additive Outliers on The Forecasts From ARIMA Models", International Journal of Forecasting, Vol 5, pp. 231-240

[3]. Brooks.C, (1997). "Linear and Non Linear Non-Forecastability of High Frequency Exchange Rates", Journal Of Forecasting, 16, pp. $125-145$

[4]. Kuan.C.M and Liu.H, (1995). "Forecasting Exchange Rate Using Feed Forward and Recurrent Neural Networks", Journal of Applied Econometrics, Vol 10, pp. 347-364

[5]. Meese. R.A, Rogoff. K, (1991). "An Empirical Assessment of Nonlinearities of Models of Exchange Rage Determination", Review of Economic Studies, Vol 58, pp. 603-618

[6]. Rossi Barbara, (2006). "Are Exchange Rates Really Random Walks? Some Evidence to Robust Parameter Instability", Macroeconomic Dynamics, Vol 10, pp. 20-38

[7]. Hong.Y and Lee.T.H, (2003). "Inference on Predictability of Foreign Exchange Rates Via Generalized Spectrum and Non Linear Time Series Models", Review Of Economics and Statistics Vol 85, pp. 1048-1062

[8]. $\quad$ Bank for International Settlements (BIS) (2010). "Triennial Central Bank Survey of Foreign Exchange and Derivatives Market Activity in 2010" (www.bis.org).

[9]. Milton F. (1953). "The Monetarist Theory of Flexible Exchange Rate Systems." In Essays in Positive Economics. Chicago: University of Chicago Press.

[10]. Hong Kong Monetary Authority (HKMA) (2005). HKMA Background Brief No. 1: Hong Kong's Linked Exchange Rate System. 2nd ed. (November): www.info.gov.hk.

[11]. "International Monetary Fund (IMF) (2006). "De Facto Classification of Exchange Rate Regimes and Monetary Policy Framework." (www.imf.org)

[12]. International Monetary Fund (IMF) (2010). "Currency CompositionofOfficialForeignExchange Reserves
(COFER)" report (www.imf.org).

[12]. International Monetary Fund (IMF) (2010). "Currency CompositionofOfficialForeignExchange Reserves
(COFER)" report (www.imf.org).

[13]. Rivard, R.J., \& Thomas, C.R., (2007). The effect of interstate banking on large bank holding company profitability and risk. Journal of Economics and Business 49 (1), 61-76.

[14]. Kashyap, A., \& Jeremy, S., (2005)."The Impact of Monetary Policy on Bank Balance Sheets," Carnegie-Rochester Conference Series on Public Policy 95.

[15]. GAO, S... (2000). Economic Globalization: Trends, Risks and Risk Prevention. CDP Background Paper No 1.

[16]. Dada, S.O... (2004). Globalization and the Future of Sovereignty. International Review of Politics and Development. 2(2): 24-39.

[17]. Kefela, Ghirmai T. (2011) "Driving Forces of Globalization in Emerging Market Economies Developing Countries" Asian Economic and Financial Review, Vol. 1, No. 2, pp. 83-94.

[18]. Dreher, Axel, Sturm, Jan-Egbert and Heinrich W. Ursprung (2008) "The Impact of Globalization on the Composition of Government Expenditures Evidence from Panel Data" Public Choice, Vol. 134, No. 3, pp. 263-292.

[19]. Rao, R. K. S. 1989. Fundamentals of Financial Management, 3rd Ed. Macmillan publishers, pp 550-644

[20]. Van Horne, J. C. \&Wachowicz, J. M. 2000. Fundamentals of Financial Management, 11th Ed. Prentice Hall Inc 